\title{
On supply function equilibria in a mixed duopoly
}

\author{
Carlos Gutiérrez-Hita ${ }^{\mathrm{a}, *}$, José Vicente-Pérez ${ }^{\mathrm{a}}$ \\ ${ }^{a}$ Departamento de Fundamentos del Análisis Económico, University of Alicante, 03071 Alicante, Spain
}

\begin{abstract}
In this paper we present a mixed duopoly model of supply function competition under uncertainty with product differentiation. We find that, regardless the nature of product heterogeneity, the best response of the private firm always arises as strategic complement. Contrary to this, state-owned firm's best response arises either as strategic complement or substitute depending on the product heterogeneity. As a result of the ex post realization of the demand uncertainty, different equilibria are reached.
\end{abstract}

Keywords: Supply Function Equilibria, Mixed oligopoly, Differentiated products. JEL classification: D43, H42, L13

\section{Introduction}

We investigate the endogenous choice of a supply function as firms' strategic variable in a mixed duopoly where a state-owned firm competes against a profit-maximizing firm. In a differentiated product setting with a numeraire good (Singh and Vives, 1984), uncertainty in the demand side is introduced (Kemplerer and Meyer, 1986). Firms' strategies arise either as strategic complements or strategic subsitutes (Bulow et al., 1985; Akgün, 2004) as a result of product differentiation, yielding the following findings. Overall, it is found that social welfare is higher as product differentiation approaches perfect complementarity. At the same time, prices and quantities increase. The contrary holds as products become substitutes. Moreover, no matter the nature of product differentiation, the state-owned firm always behaves more aggressive than the private firm producing a higher output and thus, enhancing welfare.

State-owned firms are very common in many markets such as airlines, telecommunications, railways, electricity, and banking, among other sectors. Concerning the study of mixed oligopolies, classical market structures like Cournot and Bertrand can be found. In the strand of differentiated duopolies with a stateowned firm, Haraguchi and Matsumura (2016) have compared quantity and price competition. They also endogenize the strategic variable (either quantity or price) extending previous findings by Matsumura and Ogawa (2012). In a more general setting Ghosh and Mitra (2010) also provide interesting results in the Cournot and Bertrand comparison.

To the best of our knowledge, the assumption of supply function competition (SFC, hereinafter) with heterogeneous goods in a context of a mixed oligopoly has not been yet studied. We introduce uncertainty in the demand side, which is a more realistic market environment. Indeed, SFC is a natural way to endogenize demand uncertainty because firms may offer different price-quantity pairs as a result of each demand realization. As Kemplerer and Meyer (1989) have shown, in a symmetric industry the equilibrium in supply functions is linear and unique. They also state that, under product differentiation with linear demand, the existence of a unique supply function equilibrium is guaranteed provided that the demand shock has full support.

Our results differ form Cournot and Bertrand competition because in these settings strategic interaction takes place only in one dimension, whereas in our framework firms manage a two-dimensional strategy.

\footnotetext{
* Corresponding author

Email addresses: carlosghita@ua.es (Carlos Gutiérrez-Hita), jose.vicente@ua.es (José Vicente-Pérez)
} 
Indeed, Cournot and Bertrand approaches may arise as limit cases from SFC (see, for instance, Martin, 2002, pp. 68-69).

\section{The model}

We consider an industry with two firms simultaneously producing a heterogeneous product. Firm 0 is a welfare-maximizing public firm (De Fraja and Delbono, 1990) that produces $q_{0}$, whereas firm 1 is a profit-maximizing private firm producing a quantity $q_{1}$. Both firms bear a quadratic cost function given by $C_{i}\left(q_{i}\right)=(c / 2) q_{i}^{2}$, with $c \geq 1^{1}$. The representative consumer maximizes its surplus $U\left(q_{0}, q_{1}\right)-\left(p_{0} q_{0}+p_{1} q_{1}\right)$, where $p_{i}$ and $q_{i}$ denote firm $i$ 's price and quantity, respectively, for $i=0,1$. The utility function $U\left(q_{0}, q_{1}\right)=$ $\alpha\left(q_{0}+q_{1}\right)-\left(q_{0}^{2}+2 \gamma q_{0} q_{1}+q_{1}^{2}\right) / 2$ is assumed to be strictly concave (see Singh and Vives, 1984) with $\alpha>0$ and $1-\gamma^{2}>0$. Industry inverse demand functions follow and are given by $p_{i}=\alpha-q_{i}-\gamma q_{j}(i, j=0,1$, $i \neq j)$. Product differentiation is captured by $\gamma$, where $\gamma \in \Gamma:=(-1,0) \cup(0,1)$. If $\gamma$ is negative (positive) the products are complements (substitutes). Let us assume that firms are unable to know ex ante the value of $\alpha$. Hence, from firms' point of view, the intercept of the inverse market demand is subject to an ex ante unobservable realization of $\alpha$ which has strictly positive density $f(\alpha)$ everywhere on the support $(\underline{\alpha}, \bar{\alpha}) \subset \mathbb{R}_{+}$, with $E(\alpha)=\mu$ and $V(\alpha)=\sigma^{2}$. Firms simultaneously compete in supply functions as in Kemplerer and Meyer (1989) by offering quantity-price pairs according with the linear ${ }^{2}$ function $q_{i}=\beta_{i} p_{i}$. Ex ante market clearing conditions yield prices

$$
p_{i}\left(\beta_{i}, \beta_{j}\right)=\frac{\alpha\left(1+(1-\gamma) \beta_{j}\right)}{1+\beta_{i}+\beta_{j}+\beta_{i} \beta_{j}\left(1-\gamma^{2}\right)} .
$$

A strategy for each firm is to choose the slope $\beta_{i} \geq 0$ which determines prices and quantities. Taking (1), we denote a firm's supply function by $q_{i}\left(\beta_{0}, \beta_{1}\right)=\beta_{i} p_{i}\left(\beta_{0}, \beta_{1}\right)$. The state-owned firm maximizes the expected social welfare (consumer surplus and firms' profits),

$$
\max _{\beta_{0}} \int_{\underline{\alpha}}^{\bar{\alpha}}\left(U\left(q_{0}\left(\beta_{0}, \beta_{1}\right), q_{1}\left(\beta_{0}, \beta_{1}\right)\right)-\sum_{i=0}^{1} C_{i}\left(q_{i}\left(\beta_{0}, \beta_{1}\right)\right)\right) f(\alpha) d \alpha,
$$

whereas the private firm maximizes its own expected profits,

$$
\max _{\beta_{1}} \int_{\underline{\alpha}}^{\bar{\alpha}} \pi_{1}\left(\beta_{0}, \beta_{1}\right) f(\alpha) d \alpha
$$

where $\pi_{i}\left(\beta_{0}, \beta_{1}\right)=p_{i}\left(\beta_{0}, \beta_{1}\right) q_{i}\left(\beta_{0}, \beta_{1}\right)-C_{i}\left(q_{i}\left(\beta_{0}, \beta_{1}\right)\right)$. For the sake of simplicity we assume hereinafter that $c=1$. First order conditions for the state-owned and private firms provide best response functions,

$$
\begin{gathered}
\beta_{0}\left(\beta_{1}\right)=\frac{1+2 \beta_{1}(1-\gamma)+\beta_{1}^{2}}{1+\beta_{1}\left(2-\gamma^{2}\right)+\beta_{1}^{2}\left(1-2 \gamma+\gamma^{2}\right)}, \\
\beta_{1}\left(\beta_{0}\right)=\frac{1+\beta_{0}}{2+\beta_{0}\left(2-\gamma^{2}\right)},
\end{gathered}
$$

which yield the optimal strategies reported in the following proposition.

\footnotetext{
${ }^{1}$ As stated in De Fraja and Delbono (1990), if each firm's marginal cost is constant the public firm will impose the rule of pricing at marginal cost. This is true independently of the relative efficiency of private and public firms. We abstract from this issue by considering increasing marginal costs.

${ }^{2}$ It is possible to specify a more general setting where supply functions are defined as $q_{i}=v_{i}+\beta_{i} p_{i}$. However, when marginal cost have zero intercept a supply function equilibrium of the form $q_{i}=\beta_{i} p_{i}$ exists (Kemplerer and Meyer, 1989). Moreover, as Delbono and Lambertini (2015) states, it is possible to define a linear supply function equilibrium by choosing as strategic variable $\beta_{i}$ leaving as a parameter $v_{i}$. For the sake of simplicity and without loss of generality we take $v_{i}=0$ as done in Ciarreta and Gutiérrez-Hita (2006).
} 
Proposition 1. The optimal supply functions for the state-owned and private firms are

$$
\begin{aligned}
& \beta_{0}^{*}(\gamma)=\frac{-1+2 \xi}{1-\xi\left(2-\gamma^{2}\right)}, \\
& \beta_{1}^{*}(\gamma)=\xi
\end{aligned}
$$

where $\xi$ is the unique real root of the degree 3 polynomial on $t, T_{\gamma}(t):=(2-\gamma)^{2} t^{3}+\left(2 \gamma^{3}-5 \gamma^{2}-2 \gamma+6\right) t^{2}+$ $2 \gamma t-2$.

Proof. By combining (2a) and (2b) we get the above optimal supply functions $\beta_{0}^{*}(\gamma)$ and $\beta_{1}^{*}(\gamma)$. This solution is well-defined and unique. To show this, we employ analytical tools for cubic equations (see, for instance, Press et al., 1992, Section 5.6) in order to guarantee that, for each $\gamma \in \Gamma$, the polynomial $T_{\gamma}$ has a unique real root $\xi$. Moreover, one has $T_{\gamma}(0)=-2<0$ and $\lim _{t \rightarrow+\infty} T_{\gamma}(t)=+\infty$ since $(2-\gamma)^{2}>0$, which show that $\beta_{1}^{*}(\gamma)=\xi>0$ in virtue of the well-known Bolzano's Theorem. Besides that, one can check that $T_{\gamma}\left(\frac{1}{2}\right)<0<T_{\gamma}\left(\frac{1}{2-\gamma^{2}}\right)$ for all $\gamma \in \Gamma$, which implies $\frac{1}{2}<\xi<\frac{1}{2-\gamma^{2}}$ for all $\gamma \in \Gamma^{3}$, and so $\beta_{0}^{*}(\gamma)>0$.

We point out that $\xi$ depends on $\gamma$ although, in the interest of simplicity, we do not make explicit this dependence and we just write $\xi$ instead of $\xi(\gamma)$. Furthermore, as illustrated in Figure 1, one has that the state-owned firm always behave more aggressive than the private firm, i.e., $\beta_{0}^{*}(\gamma)-\beta_{1}^{*}(\gamma)>0$ for all $\gamma \in \Gamma$. This fact shows that, as the state-owned firm is social welfare-maximizer, it has an additional incentive to increase output by cutting prices and thus, the state-owned firm's optimal supply function is always above the one chosen by the private firm.

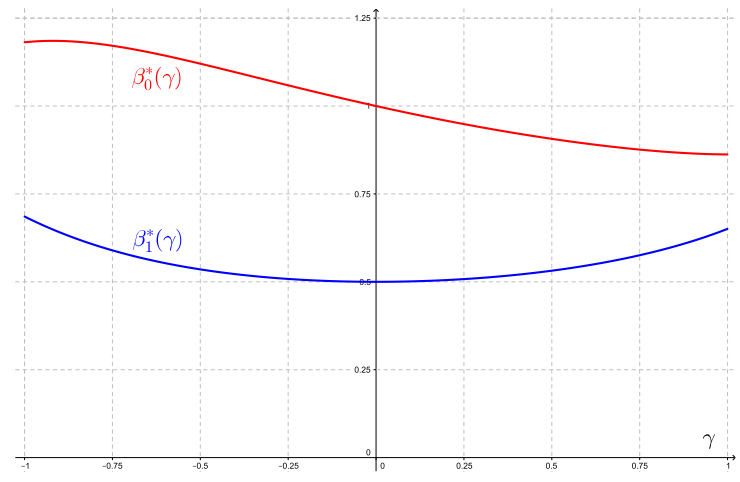

Figure 1: Optimal supply functions $\beta_{0}^{*}(\gamma)$ and $\beta_{1}^{*}(\gamma)$

\section{Results and discussion}

Once optimal supply functions $\beta_{i}^{*}(\gamma)$ have been characterized in Proposition 1 , we present in the next proposition the main findings from the best response functions in (2). The core findings of our model follows.

Proposition 2. Consider a mixed duopoly with product differentiation and SFC. Then,

(i) For $\beta_{0}>0$, the best response function of the private firm operates under strategic complementarity no matter products are complement or substitutes, i.e., $\frac{\partial \beta_{1}\left(\beta_{0}\right)}{\partial \beta_{0}}>0$ for all $\gamma \in \Gamma$.

\footnotetext{
${ }^{3}$ Following the same reasoning, one can provide tight lower and upper bounds for $\xi$. Thus, $\frac{1}{2-0.5 \gamma}<\xi<\frac{1}{2-0.6 \gamma}$ whenever $\gamma \in(-1,0)$, and $\frac{1}{2-0.4 \gamma}<\xi<\frac{1}{2-0.5 \gamma}$ whenever $\gamma \in(0,1)$.
} 
(ii) For $\beta_{1}>\frac{1}{2}$, the best response function of the state-owned firm operates under strategic substitutability (complementarity, respectively) when products are complements (substitutes, respectively), i.e., $\frac{\partial \beta_{0}\left(\beta_{1}\right)}{\partial \beta_{1}}<0$ for all $\gamma \in(-1,0)\left(\frac{\partial \beta_{0}\left(\beta_{1}\right)}{\partial \beta_{1}}>0\right.$ for all $\gamma \in(0,1)$, respectively).

Proof. Consider the best responses in (2a) and (2b). On the one hand, it follows that

$$
\frac{\partial \beta_{1}\left(\beta_{0}\right)}{\partial \beta_{0}}=\frac{\gamma^{2}}{\left(2+\beta_{0}\left(2-\gamma^{2}\right)\right)^{2}}>0
$$

for all $\gamma \in \Gamma$. On the other hand, one can see that

$$
\frac{\partial \beta_{0}\left(\beta_{1}\right)}{\partial \beta_{1}}=\frac{\gamma(2-\gamma)\left((3-2 \gamma) \beta_{1}^{2}+2 \beta_{1}-1\right)}{\left(1+\beta_{1}\left(2-\gamma^{2}\right)+\beta_{1}^{2}\left(1-2 \gamma+\gamma^{2}\right)\right)^{2}},
$$

whose sign solely depends on $\gamma$ since the denominator is positive, the factor $2-\gamma$ is positive for all $\gamma \in \Gamma$, and the factor $(3-2 \gamma) \beta_{1}^{2}+2 \beta_{1}-1$ is positive for all $\gamma \in \Gamma$ too. To see the last assertion, we consider the polynomial $S_{\gamma}(t):=(3-2 \gamma) t^{2}+2 t-1$ and observe that $3-2 \gamma>0$ for all $\gamma \in \Gamma$. Then, $S_{\gamma}(t)>0$ if and only if either $t<\underline{s}_{\gamma}:=\frac{-1-\sqrt{4-2 \gamma}}{3-2 \gamma}$ or $t>\bar{s}_{\gamma}:=\frac{-1+\sqrt{4-2 \gamma}}{3-2 \gamma}$. It can be checked that $\underline{s}_{\gamma}<0$ and $\frac{1}{2}>\bar{s}_{\gamma}$ for all $\gamma \in \Gamma$. Hence, as $\beta_{1}>\frac{1}{2}>\bar{s}_{\gamma}$, one gets $S_{\gamma}\left(\beta_{1}\right)>0$. Thus, the conclusion follows.

Observe that the assumption $\beta_{1}>\frac{1}{2}$ in Proposition $2(i i)$ is not restrictive since, according to $(i)$, one has $\beta_{1}(0)=\frac{1}{2}<\beta_{1}\left(\beta_{0}\right)<\frac{1}{2-\gamma^{2}}=\lim _{\beta_{0} \rightarrow+\infty} \beta_{1}\left(\beta_{0}\right)$ for all $\beta_{0}>0$.

Proposition 2 states that in the linear equilibrium of a SFC game, private firm's best response is upward sloping, i.e., as the state-owned firm becomes more aggressive, the optimal response of the private firm is to behave aggressive as well. Notice that the contrary holds in a Cournot game where the optimal response is to restrict output as the rival firm increases it, yielding to the well known result that quantities are strategic substitutes. In this sense, in our framework the private firm mimics Bertrand behavior. Nevertheless, the best response of the state-owned firm is upward sloping only when products are substitutes whereas it is a decreasing function under product complementarity. The intuition behind is that when products are substitutes both firms have the incentive to capture market share stealing business to the rival; in this setting, the best response of the state-owned firm is to reduce prices as long as the private firm behaves more aggressive. However, when products are complements the private firm exerts higher market power (as products are used according to a bundle consumers' willingness to pay is potentially high). Hence, when the private firm increases the price (cutting output), the best response of the state-owned firm is to behave more aggressive reducing the price and thus, increasing output.

Now we are in position to discuss more in detail the implications that firms' optimal supply functions have in prices and quantities. By combining (1) and Proposition 1, we obtain the following optimal prices and quantities,

$$
\begin{array}{rlrl}
p_{0}^{*}(\gamma) & =\frac{\alpha(1+\xi(1-\gamma))\left(1-\xi\left(2-\gamma^{2}\right)\right)}{\gamma^{2} \xi(2-\xi)}, & q_{0}^{*}(\gamma) & =\frac{\alpha(1+\xi(1-\gamma))(-1+2 \xi)}{\gamma^{2} \xi(2-\xi)}, \\
p_{1}^{*}(\gamma)=\frac{\alpha(1-\xi(2-\gamma))}{\gamma \xi(2-\xi)}, & q_{1}^{*}(\gamma)=\frac{\alpha(1-\xi(2-\gamma))}{\gamma(2-\xi)}
\end{array}
$$

which have been represented in Figure 2 below for the case $\alpha=1$. Equilibrium prices and quantities above enjoy the following properties: for any $\gamma \in \Gamma$,

(i) $\frac{\partial p_{i}^{*}(\gamma)}{\partial \gamma}<0, \frac{\partial q_{i}^{*}(\gamma)}{\partial \gamma}<0$,
(ii) $p_{1}^{*}(\gamma)-p_{0}^{*}(\gamma)>0, q_{0}^{*}(\gamma)-q_{1}^{*}(\gamma)>0$. 
Hence, as complementarity (substitutability) decreases (increases), prices and quantities decrease. In addition, private firm prices are over the state-owned firm prices, and the contrary holds for quantities (see Figure 2). These facts can be explained from the above reasoning on the best response functions features. SFC allows both private and state-owned firms manage at the same time price and quantities. Hence, when product complementarity takes place, there is weaker competition and the private firm fixes higher prices (restricting output). Accordingly, the state-owned firm behaves more aggressive by offering lower prices (and hence increasing output) aimed to partially offset the market power exerted by the private firm and thus, enhancing social welfare. As long as products become substitutes, competitiveness increases in order to capture market share and then, the private firm cuts prices. The state-owned firm reacts by cutting prices as well, although less aggressively than the private firm. As a result, prices are lower than those under product complementarity, reaching to be equal as $\gamma$ tends to one. Besides, quantity traded also decreases. The latter comes from the increasing marginal cost. Indeed, as product substitutability provides lower prices as a result of a fierce competition, firms decrease output because the marginal income from an extra unit produced is lower than its marginal cost of production. In other words, when SFC takes place, firms may adjust price and quantity by choosing the slope of the supply function in order to maximize profits (in the case of the private firm) and social welfare (in the case of the state-owned firm).

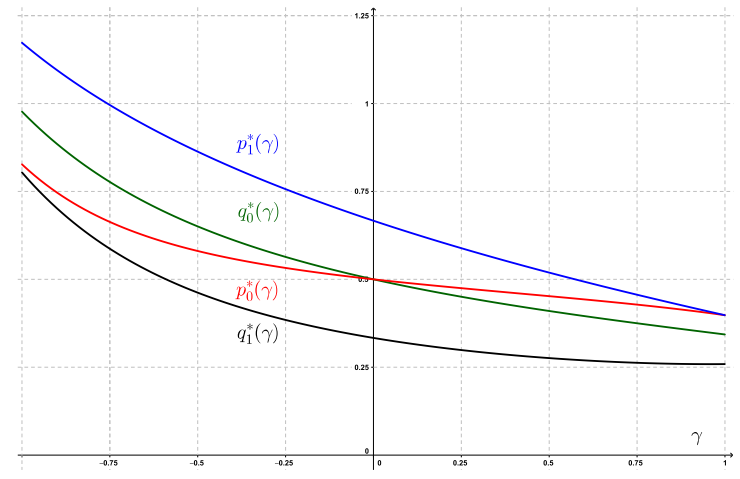

Figure 2: Optimal prices and quantities as a function of $\gamma$.

Finally, the resulting expected social welfare and private firm's expected profit can be characterized as follows,

$$
\begin{aligned}
E\left(S W^{*}(\gamma)\right) & =\left(\sigma^{2}+\mu^{2}\right)\left(U\left(q_{0}^{*}(\gamma), q_{1}^{*}(\gamma)\right)-\sum_{i=0}^{1} C_{i}\left(q_{i}^{*}(\gamma)\right)\right) \\
E\left(\pi_{1}^{*}(\gamma)\right) & =\left(\sigma^{2}+\mu^{2}\right)\left(p_{1}^{*}(\gamma)-\frac{q_{1}^{*}(\gamma)}{2}\right) q_{1}^{*}(\gamma),
\end{aligned}
$$

which are unique for each possible realization of the market demand on the support $(\underline{\alpha}, \bar{\alpha}) \subset \mathbb{R}_{+}$. Accordingly with the evolution of prices and quantities, as the degree of product differentiation changes, it can be checked that $\frac{\partial E\left(S W^{*}(\gamma)\right)}{\partial \gamma}<0$ and $\frac{\partial E\left(\pi_{1}^{*}(\gamma)\right)}{\partial \gamma}<0$ (see Figure 3, where it is assumed without loss of generality $\left.\sigma^{2}+\mu^{2}=1\right)$. The highest level of expected social welfare is attained when products are almost perfect complements $(\gamma \rightarrow-1)$ with the private firm also obtaining higher expected profits. This relationship is monotonically decreasing as product becomes susbstitutes. However, expected consumer surplus (the evaluation of the utility function at the equilibrium minus the expenditure) is maximized at $\gamma \rightarrow 1$ (see Figure 3). This fact comes from the product heterogeneity, as we explain below.

Firstly, under product complementarity market power is large. The state-owned firm tries to preserve consumer surplus (by increasing output above than produced by the private firm, and also fixing the price below than the private firm). The intuition behind is that when products are complements, the state-owned firm is aggressive in order to relax the market power exerted by the private firm. As a consequence, the 


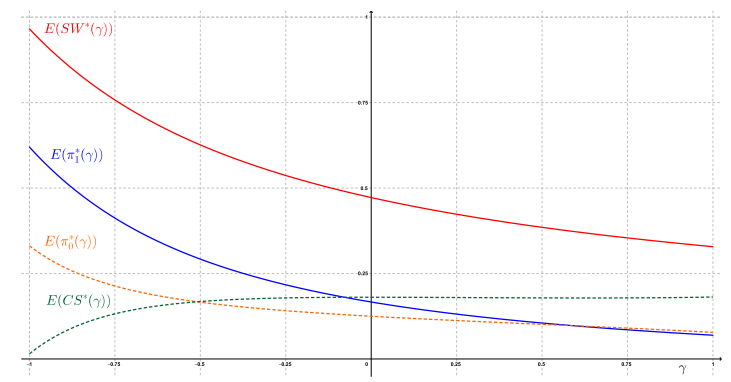

Figure 3: Expected social welfare, consumer surplus and firm's profits as a function of $\gamma$.

state-owned firm puts in the market a large amount of output which obliges to the private firm to increase output as well, enhancing the expected social welfare. Nevertheless, firms' expected profits have a higher share in social welfare.

Secondly, as product substitutability increases, expected consumer surplus benefits from lower prices, although expected social welfare and private firm's expected profits decrease. Indeed, the state-owned firm takes relatively more care about the own profits and private firm profits (by decreasing output at a higher pace than the private firm). This result arises again as a consequence of the SFC. As we pointed out above, although competitiveness is enhanced as product becomes substitutes, marginal cost increases with quantities, so firms adjust production as prices decrease in order to save costs. However, expected consumer surplus has a higher share in the expected social welfare.

To summarize, it can be said that when SFC takes place, the strategic effect induced by product complementarity is higher than the welfare effect that the state-owned firm has in the market. As a consequence, although the expected social welfare is high, the expected consumer surplus is under firms' profits when product complementarity is large. Contrary to this, the strategic effect induced by product substitutability is lower than the welfare effect that the state-owned firm has in the market. As a result, although the expected social welfare is reduced by the effect of competitiveness (but at a lower rate than it was a pure duopoly market) the expected consumer surplus is enhanced and, in fact, it is larger than private firms' profits.

\section{Acknowledgements}

C. Gutiérrez-Hita was partially supported by MINECO of Spain, Grant MTM2014-54199-P, and J. Vicente-Pérez was partially supported by MINECO of Spain and ERDF of EU, Grants MTM2014-59179-C2-1-P and ECO2016-77200-P.

\section{References}

U. Akgün. Mergers with supply function. The Journal of Industrial Economics, LII(4):535-546, 2004.

J. Bulow, J. Geanakoplos, and P. Klemperer. Multimarket oligopoly: strategic substitutes and complements. Journal of Political Economy, 93(3):488-511, 1985.

A. Ciarreta and C. Gutiérrez-Hita. Supply function vs quantity competition in supergames. International Journal of Industrial Organization, 24(4):773-783, 2006.

G. De Fraja and F. Delbono. Game theoretic models of mixed oligopoly. Journal of Economics Surveys, 4(1):1-17, 1990.

F. Delbono and L. Lambertini. On the properties of linear supply functions in oligopoly. Economics Letters, 135:22-24, 2015.

A. Ghosh and M. Mitra. Comparing bertrand and cournot in mixed markets. Economics Letters, 109(2):72-74, 2010.

J. Haraguchi and T. Matsumura. Cournot-bertrand comparison in a mixed oligopoly. Journal of Economics, 117(2):117-136, 2016.

P. Kemplerer and M. Meyer. Price competition vs. quantity competition: the role of uncertainty. The RAND Journal of Economics, 17(4):618-638, 1986.

P. Kemplerer and M. Meyer. Supply function equilibria in oligopoly under uncertainty. Econometrica, 57(6):1243-1277, 1989.

S. Martin. Advanced Industrial Economics. Blackwell Publishers, 2nd edition, 2002. 
T. Matsumura and A. Ogawa. Price versus quantity in a mixed duopoly. Economics Letters, 116(2):174-177, 2012.

W. Press, S. Teukolsky, W. Vetterling, and B. Flannery. Numerical Recipes in C: The Art of Scientific Computing. Cambridge University Press, 2nd edition, 1992.

N. Singh and X. Vives. Price and quantity competition in a differentiated duopoly. The RAND Journal of Economics, 15(4): $546-554,1984$. 